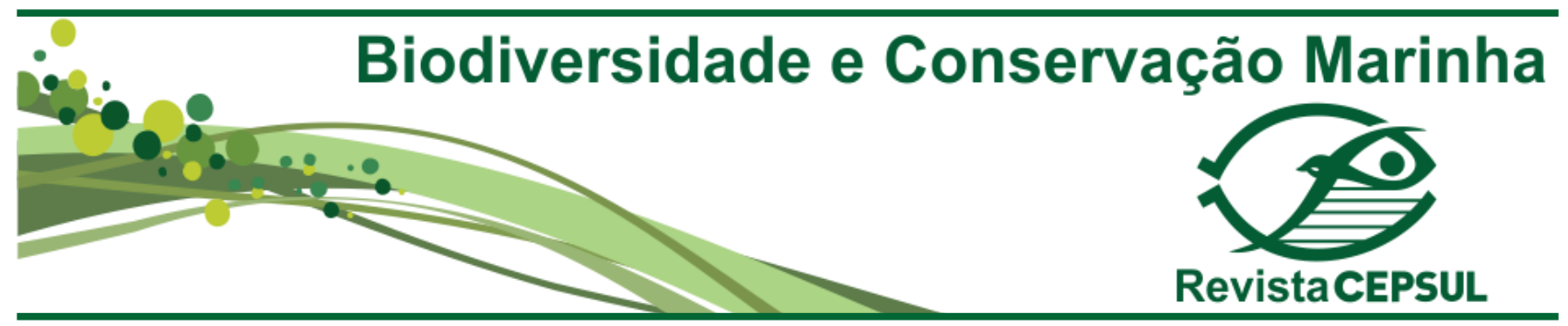

ARTIGO DE REVISÃO - ESPECIAL BABITONGA

\title{
Os manguezais e marismas da Baía Babitonga: uma síntese
}

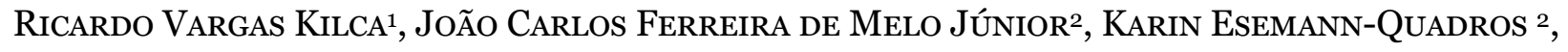 \\ LETÍCIA LARCHER 3 \& AlEsSANDRA PFUETZENREUTER ${ }^{2}$
}

\begin{abstract}
${ }^{1}$ Universidade do Estado de Santa Catarina-UDESC/CAV, Avenida Luís de Camões, 209o, CEP - 8852o-ooo, Lages, SC, Brasil, rvkilka@gmail.com;

${ }_{2}^{2}$ Programa de Pesquisa em Ciências Ambientais, Universidade da Região de Joinville - UNIVILLE, Campus Universitário s/n, Bom Retiro, CEP - 89201-972, Joinville, SC, Brasil,joao.melo@univille.br; karinesemann@gmail.com; ale_pfuetzenreuter@hotmail.com;

3 Instituto Homem Pantaneiro, Ladeira José Bonifácio, 171, CEP - 7930o-o1o, Corumbá, MS, Brasil, leticialarcher@gmail.com.
\end{abstract}

Submetido em: 24/o3/2017; Aceito em: 26/o2/2018; Publicado em: 14/o1/2019

\begin{abstract}
Resumo. Os ecossistemas de manguezais são representados principalmente por formações vegetais litorâneas singulares morfo-fisiologicamente que possuem distintas fisionomias, desde herbáceas até arbóreas, e se localizam principalmente em deltas, lagunas ou estuários. Atualmente, são reconhecidos inúmeros bens e serviços prestados por estes ecossistemas que, no entanto, estão entre os mais ameaçados do mundo. Este artigo fornece uma síntese sobre o que se sabe a respeito dos manguezais e marismas da Baía Babitonga, no nordeste de Santa Catarina. Para isso, foi realizado um levantamento bibliográfico utilizando várias bases de dados eletrônicas e fontes de dados da literatura cinzenta. Destacou-se assuntos pertinentes como a composição florística e estrutural, a produtividade, a biologia das espécies e sua vulnerabilidade, os impactos antrópicos e os estudos realizados e em andamento sobre os manguezais e marismas da Baía da Babitonga.
\end{abstract}

Palavras-chave: mangues, banhados salgados, Santa Catarina.

Abstract. The mangroves forests and saltmarshes in Babitonga Bay: a synthesis. Mangrove ecosystems are mainly represented by grasses to trees that share several highly specialized adaptations that have allowed them to colonize and thrive in intertidal areas. Mangrove forests and saltmarshes are extremely productive ecosystems that provide numerous good and services both to the marine environment and people. The present study is a compilation of the literature about saltmarshes and mangrove forests in Babitonga Bay (BB), south coast of Brazil. Systematic review of published (electronic data bases) and unpublished literature, was used. It synthesizes the knowledge as: estimates of cover and distribution, floristic, structural and forest productivity, plant species biology, status of threatened, anthropogenic impact and studies being made and new insights into the ecology of both ecosystems in BB.

Keywords: mangroves, saltmarshes, Babitonga Bay, Santa Catarina. 


\section{Introdução}

Os "manguezais lato sensu" podem apresentar-se como formações florestais (florestas de mangue) ou arbustivas, formações de gramíneas (marismas) ou juncais, que geralmente ocorrem em deltas, lagunas, estuários, banhados e alagáveis nas áreas costeiras protegidas nas regiões tropicais e subtropicais do mundo (Lugo \& Snedaker, 1974; FAO, 2007). Todos os organismos que ali vivem estão adaptados morfologica e fisiologicamente a um ecossistema altamente dinâmico quanto à salinidade, à velocidade do vento, aos regimes de maré e aos solos geralmente inconsolidados e anaeróbicos com fluxo constante de sedimentos (Duke, 2011).

As florestas de mangues ou "manguezais sensu strictu" são formações vegetais arbustivo-arbóreas que ocorrem entre as latitudes $32^{\circ} \mathrm{N}$ e $38^{\circ} \mathrm{S}$, sendo que a maior área, diversidade, altura e biomassa estão nas latitudes $5^{\circ} \mathrm{N}$ e $5^{\circ} \mathrm{S}$ e em clima equatorial (Giri et al., 2011). Estas florestas são limitadas principalmente pelas baixas temperaturas, elevada salinidade, baixa pluviosidade, baixo nível de maré e elevada topografia (Schaeffer-Novelli et al., 1990; Kathiresan \& Bingham, 2001; SchaefferNovelli, 2016). No planeta, elas ocorrem em apenas 0,5\% das áreas costeiras e são as florestas tropicais mais ameaçadas do planeta (Duke et al., 2007). Embora com pequena cobertura, os manguezais desempenham bens e serviços de importância regional e global relacionados com a sustentabilidade ecológica (p. ex.: habitat e alimento para animais, acumulação de sedimentos, retenção de poluentes, nutrientes e ciclagem de matéria orgânica), segurança ambiental (mitigação de tsunamis, ciclones, inundações e gases de efeito estufa), economia industrial (cerca de 80\% da captura global de peixes e fonte de matéria-prima para a aquicultura) ou de subsistência (madeira para construção e combustível, pesca amadora, apicultura) e o lazer/turismo (pesca desportiva, observação de aves) (Sandilyan \& Kathiresan, 2012; UNEP, 2014; UN, 2016a).

Os banhados salgados ou marismas são formações vegetais costeiras dominadas por gramíneas, podendo ter ainda outras plantas herbáceas (perenes ou anuais) e pequenos arbustos (menores de 0,5m de altura) adaptados ao estresse salino e fluxo da maré (Costa \& Davy, 1992; UN, 2016b). Sua distribuição geográfica preferencial abrange latitudes médias e altas em todo o mundo e são amplamente substituídos pelas florestas de mangues nos trópicos e subtrópicos (UN, 2016). Os fatores que determinam o desenvolvimento e a estrutura das marismas são a temperatura (atmosférica e da água oceânica), a ação da maré, as ondas, o influxo de água-doce, o suprimento de nutrientes e a topografia (Schaeffer-Novelli, 2016). As funções das marismas são similares aos manguezais quanto à retenção de sedimentos, sumidouro de carbono, ciclagem de nutrientes, manutenção da fauna, estabilização das zonas costeiras, além de funcionar como zona tampão de nutrientes e poluentes (Robertson \& Duke, 1990; UN, 2016).

No Brasil, os manguezais e marismas são classificados como Formação Pioneira de Influência Fluviomarinha (IBGE, 2012). O país apresenta um litoral com $7.400 \mathrm{~km}$ de extensão que abriga 962,6 ha de manguezais (lato sensu) sendo considerado o terceiro país com a maior área deste ecossistema no mundo (FAO, 2007; Giri et al., 2011). Considerando o enorme litoral brasileiro e a diversidade de condições abióticas e bióticas existentes, SchaefferNovelli et al. (1990) dividiram a região costeira em oito unidades fisiográficas onde pode se encontrar padrões distintos para composição e estrutura de manguezais e marismas em cada uma destas regiões. O litoral de Santa Catarina pertence ao setor VII (desde Cabo Frio até Torres) que se destaca pela proximidade da Serra do Mar com o oceano que formam inúmeras praias entre as montanhas, uma grande precipitação pluviométrica no ano todo e menor amplitude de maré em relação a região nordeste e norte do litoral brasileiro (SchaefferNovelli et al. 1990).

Com relação a diversidade de espécies arbóreas, os manguezais brasileiros são pobres, sendo registradas sete espécies distribuídas em quatro gêneros (FAO, 2007). As florestas de 
mangues no norte do país (Amapá, Pará e Maranhão) são os mais diversas, com árvores que podem atingir 40-45m de altura (Rhizophora harrisonii Leechman) e com até 1m de diâmetro do caule (Avicennia sp.) (FAO, 2007). Por outro lado, os manguezais do sul do Brasil têm seu limite em Laguna, Santa Catarina ( $28^{\circ}$ 30'S), onde ocorrem duas espécies que podem atingir chegar até $2 \mathrm{~m}$ de altura (Laguncularia racemosa (L.) C. F. Gaertn) ou até $9 \mathrm{~m}$ de altura e $22 \mathrm{~cm}$ de diâmetro do caule (Avicennia schaueriana Stapf \& Leechman ex Moldenke) (Schaeffer-Novelli, 1990; Soares et al., 2012). Cerca de $25 \%$ dos manguezais já foram destruídos no país (ICMBio, 2018) e, embora protegidos por lei, apenas recentemente foi elaborado um plano de ação nacional para a conservação de dezenas de espécies representativas deste ecossistema ao longo do litoral brasileiro (ICMBIO, 2015).

No Brasil, as marismas estão mais representadas nos estados de Santa Catarina (principalmente na Lagoa de Santo Antônio em Laguna) e Rio Grande do Sul (Laguna dos Patos em Rio Grande). Em Santa Catarina, podem haver diversas espécies herbáceas sendo as mais frequentes Spartina alterniflora Loisel. e Spartina densiflora Brong. (Poaceae) que ocupam largas franjas frente aos manguezais e estuários, ou formando pequenas ilhas (de até 50m de diâmetro) (Sobrinho et al., 1969; Soriano-Sierra et al., 2015; Rosa et al., 2013).

Este estudo teve como objetivo apresentar uma revisão da bibliografia publicada e não publicada sobre as florestas de mangues e as marismas na região da Baía Babitonga (Figura 1) abordando assuntos como: a cobertura e a distribuição, a composição florística e estrutural, a produtividade, a biologia das espécies, a vulnerabilidade e os impactos antrópicos e os estudos realizados e em andamento sobre estes ecossistemas costeiro.

\section{Materiais e métodos}

Neste estudo de revisão bibliográfica foram incluídos trabalhos teóricos metodológicos, quantitativos ou qualitativos, que analisaram as florestas de mangues (aqui também de- nominado como manguezais) e marismas exclusivamente do estuário da Baía Babitonga. Foram excluídos os resultados obtidos em relatórios técnicos de licenciamentos ambientais, bem como aquelas informações breves em textos históricos. Na estratégia de busca, utilizaram-se alguns recursos informacionais como a base de dados eletrônica do portal de periódico da CAPES, duas bibliotecas digitais (Banco de Teses da CAPES e SciELO) e um buscador acadêmico (Google Acadêmico). Além das bases de dados de publicações científicas indexadas, explorou-se a literatura cinzenta, que veicula trabalhos não publicados como resumos de congresso e monografias, dissertações, teses e relatórios técnicos institucionais. Para esta pesquisa também foram utilizados os acervos das bibliotecas das universidades da região (FURB, UNIVILLE, UFSC, UFPR e UNIVALI) e os bancos de dados de Anais de Congressos da Sociedade de Botânica do Brasil e Sociedade de Ecologia do Brasil. As palavras-chave utilizadas para a busca em todas as fontes foram: "manguezais da Baía Babitonga", "manguezais Santa Catarina", "Baía Babitonga", "marismas Santa Catarina" e "marismas da Baía Babitonga", "mangroves Baía Babitonga", "mangroves Santa Catarina", "saltmarsh Baía Babitonga", "Saltmarsh Santa Catarina".

\section{Resultados e discussão}

\section{A distribuição e a cobertura dos manguezais e marismas}

Informações sobre a extensão, limites e cobertura dos manguezais na Baía Babitonga (BB) foram registrados em cinco principais estudos. O cadastro realizado pela FATMA (1984) apud IBAMA (1998) cita a ocorrência de manguezais nas ilhas do Rio Palmital, Lagoa do Saguaçú, assim como, ocorrendo nas terras baixas ao norte e sul do Rio Palmital, além de marismas no trecho sul do Canal do Linguado (Figura 1).

Silva (1995) relatou em detalhes a região de abrangência dos manguezais na BB, presentes na região do canal de Três Barras, que abrange os municípios de Joinville, Garuva e 


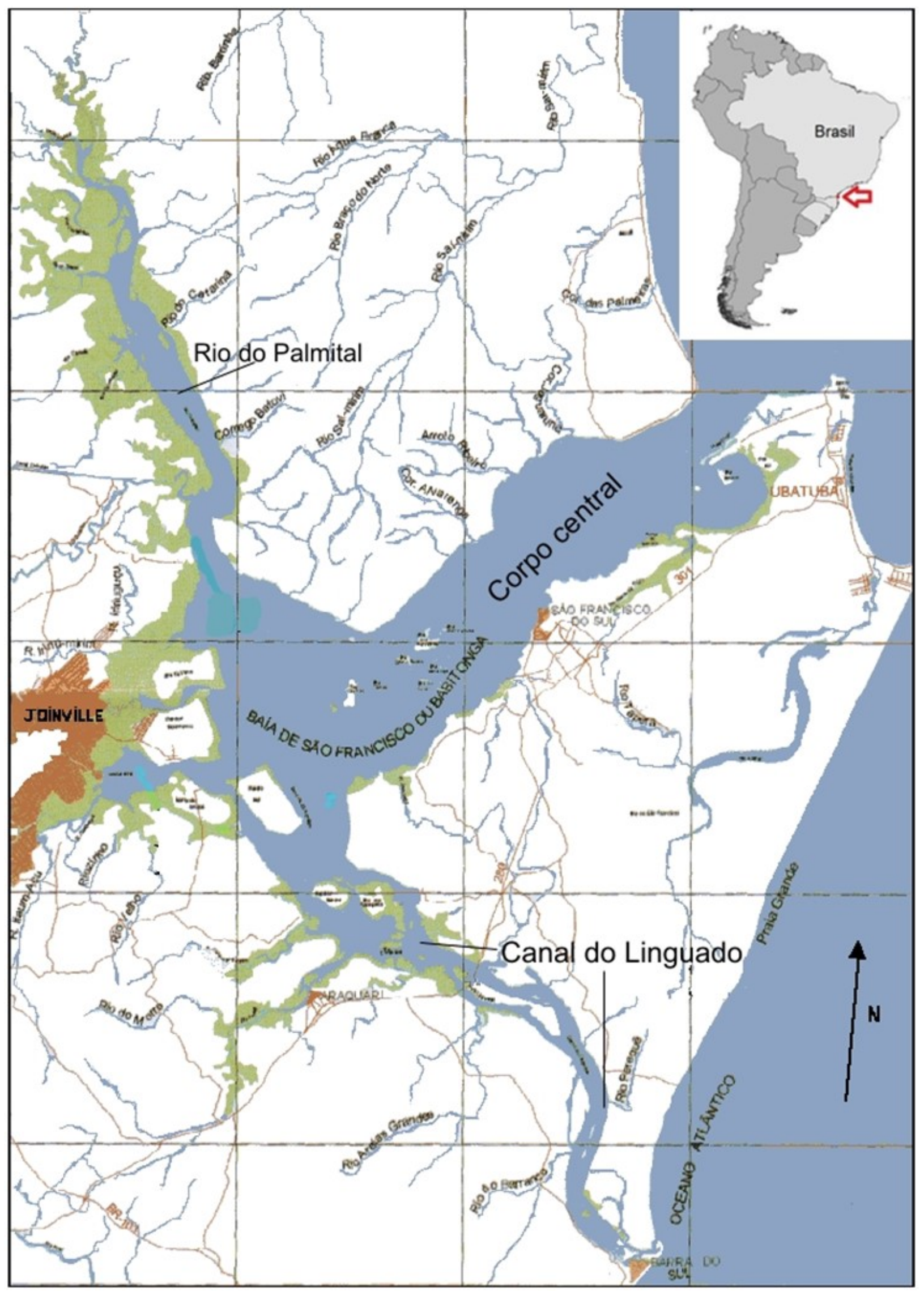

$\sim$ Sistema Viário $\sim$ Hidrografia Arca Urbana Bala/Oceano Mangue (6.201,54 ha.)

Figura 1. Localização da Baía Babitonga no sul do Brasil e a distribuição dos manguezais nos principais setores da BB (canal do Linguado, Rio Palmital e corpo central). Adaptado Tognella (1998) e Hansel (2000). 
São Francisco do Sul, onde se encontra uma densa rede hídrica com 14 córregos e rios e no entorno das Lagoas do Saguaçu e Varador. Manguezais ocorrem no trecho sul da BB, do município de Araquari e Balneário Barra do Sul (Canais Ipiranga e Linguado) e na foz do Canal do Linguado (Balneário Barra do Sul); ao norte o limite de ocorrência é entre os municípios de Itapoá-Guaratuba. Também são registrados manguezais na entrada da $\mathrm{BB}$, tanto na porção continental (Ponta do Barbosa e Praia da Figueira do Pontal), como na porção insular (morro João Dias e Ponta do Capri). Nas ilhas, os manguezais ocorrem em 51 das 57 ilhas existentes no Canal do Linguado, em todas as 37 ilhas do setor norte da BB e em apenas duas ilhas do corpo central da BB (ver banco atual de imagens em https:// www.babitongaativa.com/).

Fisher (1983) apud Silva (1995) estimou em $75 \mathrm{~km}^{2}$ a área de mangues existentes na $\mathrm{BB}$, onde $35 \%$ destes estariam destruídos. Tognella (1998) avaliou a cobertura de florestas de mangues na BB em 6.201,54 ha, mas chamou a atenção que a estimativa estava superestimada devido às idades das imagens orbitais (1970) e a técnica utilizada. A autora também considerou que os manguezais mais preservados estariam localizados no Canal do Linguado e os manguezais mais alterados na região de Joinville. Estudos posteriores indicaram que as maiores áreas de manguezais atualmente estariam localizadas no entorno do rio Palmital (Oliveira, 2006; Grace et al., 2008).

Em estudo recente realizado por Fava (2016), foram contabilizadas 206 ilhas na Baía (3.447 ha), dispostas em seis grupos: Rio Palmital (67), Lagoa do Saguaçú (32), Canal do Linguado Norte (36), Canal do Linguado Sul (41), Central (27) e Foz (3). Segundo a autora, o manguezal cobre $59,54 \%$ e as marismas 21,9\% destas ilhas.

Desta forma, constata-se que são bem conhecidos os locais de ocorrência dos manguezais, mas os e dados da ocorrência de marismas são incipientes. Além disso, a estimativa de cobertura remanescente dos manguezais (florestas de mangues e marismas) é desatuali- zada. A relevância destes manguezais e marismas associados foi reconhecida dentro da atual política de preservação da biodiversidade do Brasil, onde a Baía da Babitonga é classificada como de importância extremamente alta para conservação onde é recomendada a criação de unidades de conservação (CEPSUL, 2005). Esta categoria de importância para conservação se deve porque $75 \%$ de todas as florestas de mangues existentes no estado de Santa Catarina ocorrem na BB (Tognella, 1998). Portanto, a elaboração de um estudo que retrate a distribuição e a cobertura atual das florestas de mangues e de marismas é o primeiro passo estratégico para elencar a escolha de áreas chave para preservar e conservar estes ecossistemas na Baía Babitonga.

\section{Florística e estrutura dos man- guezais e marismas}

$\mathrm{Na}$ revisão realizada foram identificados apenas quatro principais estudos indexados em periódicos científicos, uma tese de doutorado, dois em resumos de reuniões científicas e alguns comentários isolados em revistas científicas, livros, resumos de congressos e trabalhos de conclusão de cursos. De forma geral, três estudos que abordaram as mudanças na estrutura e na florística dos manguezais foram realizados em média escala e três estudos em pequena escala na $\mathrm{BB}$.

Tognella (1998) caracterizou a composição e a estrutura de trechos de manguezais (o,2 ha amostral) do tipo franja em quatro regiões distintas da BB. Os manguezais próximos de Joinville apresentaram bosques com monodominância de Avicennia schaueriana (7 a 12 m altura) e pouca presença de Laguncularia racemosa e Rhizophora mangle. Os manguezais da Ilha do Mel apresentaram similar estrutura (5 a $13 \mathrm{~m}$ de altura) e comunidades com monodominância de L. racemosa ou dominância conjunta de $L$. racemosa com $A$. schaueriana. Por outro lado, no Canal do Linguado (CL) e no Rio Palmital (RP), os manguezais apresentaram os maiores portes ( 7 a $13 \mathrm{~m}$ de altura) e valores similares em área basal. No CL predominaram comunidades com elevadas densidades de A. schaueriana e L. racemosa e 
poucas com abundância de $R$. mangle. No rio Palmital foram registrados mangues com monodominância de $L$. racemosa e baixa presença de A. schaueriana e R. mangle. A autora destacou a ocorrência de manguezais com elevado porte (até $15 \mathrm{~m}$ de altura), se tratando estar próximo do limite sul de ocorrência na América do Sul.

Dornelles et al. (2006) realizaram inventários comparativos entre manguezais da região sul e norte do Canal do Linguado (CL) (área total amostrada de 0,6 ha). Os autores citaram oito espécies vegetais de ocorrência na região de estudo: Acrosticum aureum L., $R$. mangle, A. schaueriana, L. racemosa, Talipariti tiliaceum (L.) Fryxell, Spartina alterniflora, Struthanthus vulgaris (Mart.) e Phoradendron sp. Na região do trecho norte do CL estariam os mangues mais preservados, com maior largura e sobre solos mais argilosos. Nestes ambientes predominaram em densidade a espécie $L$. racemosa, seguido de $A$. schaueriana e $R$. mangle. No entanto, A. schaueriana foi a espécie mais importante (58\% das comunidades) devido seus maiores valores em área basal $\left(23,26 \mathrm{~m}^{2} / \mathrm{ha}\right)$, diâmetro dos troncos $(40,6 \mathrm{~cm})$, altura $(15 \mathrm{~m})$ e densidade na regeneração natural. No trecho sul do CL, onde ocorrem os mangues mais impactados, sobre solos mais arenosos e com menor flutuação do nível de água, as maiores densidades foram de L. racemosa, seguido de $R$. mangle, T. tiliaceum e A. schaueriana. Neste trecho, L. racemosa também foi a espécie mais importante pela grande densidade, pequenos diâmetros de troncos e grande área basal. Assim, os distintos grupos florísticos e estruturais entre as regiões norte e sul do Canal do Linguado refletiram as diferenças no estado de conservação, hidrologia e sedimentos predominantes entre as duas áreas. Essas características condicionaram manguezais monodominantes com $A$. schaueriana ou associações com $L$. racemosa e A. schaueriana que predominam no setor norte do CL e $L$. racemosa com maior diversidade de espécies no setor sul. Os autores ainda destacaram que os manguezais mais próximos dos ecossistemas terrestres adjacentes apresentaram uma baixa estatura (1,5 $\mathrm{m}$ a $3,5 \mathrm{~m}$ de altura).
Um estudo muito esclarecedor sobre os aspectos da mudança florística e estrutural em grande escala na BB foi realizado por Cunha et al. (2006). Neste estudo, os autores avaliaram oito sítios (o,37 ha de área amostral) ao longo de toda a extensão da Baía. Os dados revelaram que as três espécies arbóreas possuíam ampla distribuição geográfica, mas com maior abundância de $L$. racemosa. Houve a tendência de aumento da densidade e diminuição do porte (altura e diâmetro do caule das plantas) com relação à diminuição da frequência de alagamento, ou seja, das florestas de mangue próximas ao corpo d'agua (bosques de franja) em direção às porções mais internas das florestas (mangues intermediários e de bacia). Além disso, as comunidades com elevada dominância de $R$. mangle foram poucas representativas e mais associadas aos ambientes mesoalinos (com baixa a média salinidade da água oceânica) e com baixa frequência de alagamento (porções mais interiores da floresta), apresentando assim, baixa estatura, elevada densidade e biomassa. Comunidades dominadas por $A$. schaueriana foram caracterizadas pela baixa densidade de plantas e elevada biomassa (plantas com as maiores altura e diâmetro dos caules) e ocorrem preferencialmente em ambientes de franja (maior frequência de alagamento) em águas meso e eurialinas (salinidade média e normal das águas). Por outro lado, comunidades dominadas por $L$. racemosa podem ocorrer em ambientes com baixa frequência de alagamento (bosques intermediários e de franja) por águas eurialinas, formando assim, comunidades com baixo porte e comunidades localizadas nas franjas, em águas com baixa salinidade (oligoalinas), onde apresentam elevada densidade de plantas e biomassa. De forma geral, os autores consideraram que a frequência de alagamento, e o seu papel na formação e modificação dos sedimentos, teriam maior papel nas mudanças florísticos estruturais do que a salinidade das águas.

Três estudos de casos avaliaram as mudanças na composição florística e estrutura das florestas de mangues em pequena escala espacial. Kilca et al. (2011) avaliou um pequeno trecho de mangue (o,13 ha) próximos da foz da 
BB. Os autores demonstram que as porções de mangues sobre solos mais arenosos (nove parcelas) apresentaram a predominância de $L$. racemosa (maior porte e valor de importância) e outra porção de mangue (quatro parcelas) em solos lodosos (distante apenas $2 \mathrm{~m}$ do trecho anterior) apresentaram maior densidade e maior área basal de $R$. mangle. Sousa et al. (2016) instalaram duas parcelas de $100 \mathrm{~m}^{2}$ paralelas $\left(400 \mathrm{~m}^{2}\right)$ e não comprovaram mudanças florísticas e estruturais relevantes quando não ocorrem mudanças na granulometria do sedimento. Larcher (2016) realizou uma amostragem em $750 \mathrm{~m}^{2}$ de manguezais e não identificou mudanças significativas no gradiente de inundação franja - interior, onde L. racemosa permaneceu como a espécie mais densa, seguido de $R$. mangle e A. schaueriana.

Alguns estudos qualitativos baseado em observações pessoais também trouxeram informações adicionais sobre o efeito da zonação (alagamento e/ou sedimento) nos manguezais da BB. Schaeffer-Novelli et al. (1990), caracterizaram um trecho de manguezal próximo de Joinville e relataram que A. schaueriana atingiu grande porte e densidade em ambientes de franja e que $L$. racemosa seriam menores e mais densas em manguezais mais interiores do tipo bacia. Além disso, destacaram o decréscimo da estatura das populações de todas as espécies na medida em que se distanciavam das margens da lagoa. Oliveira \& Treter (2007) realizaram um estudo para avaliar a relação entre a composição granulométrica e mineralógica dos sedimentos e as espécies arbóreas dos manguezais do rio Palmital. Este estudo registrou uma tendência de que em sedimentos mais grosseiros (embora nem sempre) na parte interna das florestas podem ocorrer preferencialmente $L$. racemosa e $R$. mangle. Na porção mais próxima da lâmina da água, os autores registraram a presença de sedimentos mais finos e a predominância de A. schaueriana.

Estes resultados indicaram que o tipo de sedimento pode ser o fator mais determinante de mudanças florísticas e estrurais em pequena escala e o nível de alagamento e/ou salinidade podem ser fatores condicionantes dos manguezais em média e larga escala na BB. Além disso, as três espécies arbóreas podem ocorrer ao longo de toda a BB, sendo que $L$. racemosa é a espécie mais comum e com ampla distribuição, $A$. schaueriana é mais frequente na região próxima de Joinville e $R$. mangle é a espécie menos frequente e com poucas comunidades monodominantes.

Um levantamento florístico detalhado em diversas fitofisionomias no entorno da Baía Babitonga foi realizado por Berger (2008), que apresentou uma lista florística conjunta para os manguezais e as marismas na Vila da Glória e em oito ilhas. Para estes locais, o autor identificou 18 espécies vegetais, sendo três espécies arbóreas (já citadas por outros autores), cinco herbáceas e nove epífitas (ver Tabela 1). Para as marismas o autor listou duas espécies herbáceas (Paspalum vaginatum Sw, Spartina alterniflora Loisel) e todas da lista ocorrentes nos manguezais. A maioria das epífitas nos manguezais listadas pelo autor é da família Bromeliaceae, (Tabela 1) onde duas destas espécies foram consideradas restritas apenas às florestas de mangues da BB: Aechmea ornata Baker e A. kertesziae Reitz, a última sendo considerada endêmica. Na periferia dos manguezais, o autor citou uma diversidade muito maior de espécies (6o esp.), pertencentes à diversas famílias botânicas e formas de vida. São espécies típicas de outros ecossistemas que apenas ocasionalmente ocorrem em zonas de transição com os manguezais e, por isso, não serão listadas nesta revisão.

Embora o estudo de Berger (2008) represente a lista florística mais completa para os manguezais da $\mathrm{BB}$, pode-se considerar que o número de espécies vegetais para este ecossistema tende a aumentar. Muitas espécies de lianas consideradas pelo autor como de ocorrência em zonas periféricas também ocorrem no interior dos manguezais ribeirinhos e de franja (Kilca com. pess.). Além disso, muitas espécies de epífitas (Orchidaceae) listadas pelo autor para as florestas de terra firme também são encontradas regularmente nos mesmos manguezais (Kilca com. pess.).

Além de Berger (2008), não foram en- 
Tabela 1. Lista das espécies vegetais mais conspícuas nos manguezais e marismas na Baía BabitongaSC de acordo com os estudos mais significativos. F.V. = formas de vida (Ep.= epífitas, Apa. = epífita parasita, Av.= árvores, $\mathrm{Ab} .=$ arbustos, $\mathrm{He} .=$ herbáceas $) . \mathrm{Eco}=$ ecossistema $(\mathrm{Mn}=$ manguezal, $\mathrm{Ma}=$ marisma). Autores: 1. Dornelles et al. (2006), 2. Berger (2008).

\begin{tabular}{|c|c|c|c|c|}
\hline Família & Nome científico & F.V. & Eco. & Ref. \\
\hline Acanthaceae & Avicennia schaueriana Stapf \& Leechm. ex Moldenke & Av & $\mathrm{Mn}$ & 1,2 \\
\hline \multirow{5}{*}{ Bromeliaceae } & Aechmea caudata Lindm. & Ep. & Mn & 2 \\
\hline & Aechmea kertesziae Reitz & Ep. & $\mathrm{Mn}$ & 2 \\
\hline & Aechmea ornata Baker & Ep. & $\mathrm{Mn}$ & 2 \\
\hline & Vriesea philippocoburgii Wawra & Ep. & Mn & 2 \\
\hline & Vriesea vagans (L.B. Sm.) L.B. Sm. & Ep. & $\mathrm{Mn}$ & 2 \\
\hline \multirow{2}{*}{ Combretaceae } & Conocarpus erectus L. & $\mathrm{Ab}$ & Mn & 1 \\
\hline & Laguncularia racemosa (L.) C.F. Gaertn & Av & $\mathrm{Mn}$ & 1,2 \\
\hline Cyperaceae & Fimbristylis spadicea (L.) Vahl & He. & $\mathrm{Mn}$ & 2 \\
\hline Gesneriaceae & Codonanthe devosiana Lem.: & Ep. & $\mathrm{Mn}$ & 2 \\
\hline \multirow[b]{2}{*}{ Loranthaceae } & Struthanthus vulgaris Eichler ex Mart & Epa & $\mathrm{Mn}$ & 2 \\
\hline & $\begin{array}{l}\text { Struthanthus polyrrhizos (Mart. ex Roem. \& Schult.) } \\
\text { Martius ex G. Don: }\end{array}$ & Epa & Mn & 2 \\
\hline Malvaceae & Talipariti tiliaceum L. & $\mathrm{Ab}$ & $\mathrm{Mn}$ & 1,2 \\
\hline \multirow{4}{*}{ Poaceae } & Paspalum vaginatum $\mathrm{Sw}$ & $\mathrm{He}$ & $\mathrm{Mn}$ & 2 \\
\hline & Spartina alterniflora Loisel & $\mathrm{He}$ & $\begin{array}{l}\mathrm{Mn} \\
\mathrm{Ma}\end{array}$ & 1,2 \\
\hline & Spartina densiflora Brongn. & $\mathrm{He}$ & & 1,2 \\
\hline & Sporobolus virginicus (L.) Kunth & $\mathrm{He}$ & $\begin{array}{l}\mathrm{Mn} \\
\mathrm{Ma}\end{array}$ & 2 \\
\hline Pteridaceae & Acrostichum danaeifolium Langsd. \& Fisch & $\mathrm{He}$ & $\mathrm{Mn}$ & 1 \\
\hline Rhizophoraceae & Rhizophora mangle L. & Av & $\mathrm{Mn}$ & 1,2 \\
\hline Viscaceae & Phoradendron crassifolium (Pohl ex DC.) Eichler & Epa & $\mathrm{Mn}$ & 1,2 \\
\hline
\end{tabular}

contrados registros de estudos específicos sobre as marismas na Baía Babitonga, indicando a necessidade urgente de mapeamento e caracterização destes ecossistemas. No entanto, existem diversos estudos publicados sobre marismas em Santa Catarina, tendo maior registro aqueles realizados em Florianópolis e Laguna (Sobrinho et al., 1969; Klein et al., 1981; Panitz, 1987, 1992; Soriano-Sierra, 1990, 1999; Souza et al., 1992; Costa \& Davy, 1992; Soriano -Sierra et al., 2015; Valgas, 2009). Estes estudos indicaram uma riqueza média de 10-20 espécies herbáceas, o que aumenta a estimativa de diversidade prevista para as marismas na BB.

\section{Biologia e vulnerabilidade das es- pécies de mangues e marismas}

Do ponto de vista funcional, as espécies de manguezal são capazes de apresentar respostas adaptativas à interação com fatores abióticos que atuam em diferentes escalas espaciais e temporais e podem refletir na sua distribuição. Foi registrado apenas um estudo sobre a biologia das espécies de mangues na $\mathrm{BB}$. Bartz et al. (2015) demonstrou diferenças nos atributos morfoanatômicos foliares e da arquitetura da planta em populações de L. racemosa distribuídas nos ambientes de manguezal e área de transição manguezal/restinga na Lagoa do Saguaçu, em Joinville. Em ambientes de franja, L. racemosa apresentou árvores com maiores valores na área foliar, altura, diâmetro dos caules e número de folhas senescentes e menores valores em densidade de copa e percentual de folhas predadas. Por outro lado, as populações das áreas de transição apresentaram menor tamanho de folhas e volume foliar 
e maiores valores de área foliar, área específica foliar e densidade foliar. Para os autores, as condições ambientais contrastantes com expressivas diferenças na salinidade da água, alagamento e nutrientes dos solos refletiram nas diferenças entre as populações avaliadas.

Quanto ao estado de conservação das três espécies arbóreas (L. racemosa, $R$. mangle e A. schaueriana), a União Internacional para a Conservação da Natureza (UICN, 2017) considera todas no status de "pouco preocupante". Dentro do Plano de Ação Nacional para Conservação das Espécies Ameaçadas e de Importância Socioeconômica do Ecossistema Manguezal, que inclui 74 espécies, as mesmas espécies são consideradas como de importância socioeconômica e não ameaçadas (PAN Manguezais, 2015). Estas mesmas espécies também não constam na lista das espécies ameaçadas do Estado de Santa Catarina (CONSEMA, 2014).

\section{A produtividade dos manguezais}

Para a Baía Babitonga, foram encontrados três estudos sobre a produtividade em manguezais. Silva (2001), avaliou alguns indicadores ecológicos para as três espécies arbóreas de manguezal e sua relação com diferentes condições ambientais da BB. Primeiramente, o autor revelou que o padrão de queda da serapilheira esteve fortemente relacionado com a sazonalidade. A produção média diária de biomassa morta foi de $1,20 \mathrm{gPSm}^{-2} \mathrm{dia}^{-1}$. A maior produtividade $\left(1,79 \mathrm{gPSm}^{-2} \mathrm{dia}^{-1}\right)$ esteve relacionada à estação amostral localizada no rio Palmital, por ser uma área em bom estado de conservação, enquanto as mais baixas (o,81 $\mathrm{gPSm}^{-}$ ${ }^{2} \mathrm{dia}^{-1}$ e $1,01 \mathrm{gPSm}^{-2} \mathrm{dia}^{-1}$ ) ocorreram em áreas mais impactadas por rejeitos orgânicos e corresponderam, respectivamente, às estações amostrais de Joinville e do canal do Linguado. O estudo de Cunha et al. (2006) avaliou a função da salinidade e alagamento na produtividade de mangues. Este estudo revelou que a maior produtividade das florestas de mangues, em termos de altura da planta, diâmetro caulinar e alocação de biomassa, esteve condicionada aos ambientes oligoalinos e com alta frequência de inundação, enquanto a menor produtividade esteve relacionada a ambientes eurialinos e mesoalinos com alta frequência de inundação. A tolerância à salinidade é reconhecida como o fator vital (Kathiresan \& Bingham, 2001; Parida \& Jha, 2010). Em geral, a salinidade afeta a produtividade dos manguezais pelo déficit de água, pela toxidez provocada por íons que geram desequilíbrio nutricional e, indiretamente, mediando competições interespecíficas (Lüttge, 2008; Parida \& Jha, 2010).

Agnolon (2008) avaliou a produção comparativa de serapilheira entre três florestas de mangues ao sul e três florestas ao norte do Canal do Linguado (CL). As florestas ao norte do CL produziram mais que o dobro de serapilheira $\left(0,956\right.$ g.m ${ }^{2} \cdot$ dia $^{-1}$ ou 3,48 t.ha/ano $\left.{ }^{-1}\right)$ em relação às florestas do sul $\left(0,474\right.$ g.m ${ }^{2} \cdot$ dia $^{-1}$ ou 1,73 t/ha-1.ano-1). Essa diferença foi decorrente da espécie dominante em cada região. Assim, R. mangle foi a espécie que mais contribuiu na produção de serapilheira no sul (0,178 g. $\mathrm{m}^{2}$.dia-1) e A. schaueriana a espécie com maior produção no norte do CL (o,461 g.m².dia-1). $\mathrm{O}$ aumento da produção seguiu a relação com o aumento da área basal e porte da floresta (Dornelles et al., 2006). As espécies também variaram a sua produção de serapilheira em períodos distintos do ano.

\section{Os impactos ambientais nos man- guezais e marismas}

Desde seu descobrimento (1504) até a metade do século XIX, a Baía Babitonga apresentou poucos impactos antrópicos, pois a economia dos moradores era basicamente de subsistência ou de baixa intensidade devido a pequena taxa de colonização (Silva, 1995). Dentro de um cenário crescente de ocupação e uso do solo há décadas são relatados vários tipos de impactos antrópicos na BB que refletem seus efeitos nos manguezais da região.

Atualmente, o entorno da baía Babitonga abriga seis municípios que em conjunto apresentam uma população com quase 700.00o habitantes: Joinville (569.645 hab.), São Francisco do Sul (49.658 hab.), Araquari (33.867 hab.), Itapoá (18.749 hab.), Garuva (17.134 hab.) e Barra do Sul (10.073 hab.) (IBGE, 2016). Nestes municípios encontram-se 
o maior parque industrial (Joinville) e o segundo sistema portuário (São Francisco do Sul e Itapoá) de Santa Catarina, além de um terminal petrolífero (São Francisco do Sul).

Nesta revisão foi encontrado um expressivo número de trabalhos publicados que retratam os impactos ambientais nos manguezais da BB. Duarte (1988) chamou a atenção para o assoreamento da BB devido aos desmatamentos, às atividades de terraplanagens $\mathrm{e}$ aos locais de extração de solos nas áreas mais elevadas. A poluição das águas e sedimentos dos mangues devido ao fluxo de contaminantes agrícolas, industriais e urbanos foram citados por diversos autores (Duarte, 1988; Karger, 1996; Grace et al., 2008), podendo causar danos não só na flora e fauna como também na saúde humana (Bertolli \& Zanotelli, 2009). Dentre os principais poluentes existentes nos sedimentos dos manguezais estão os derivados de petróleo (Hansel, 2000; Alexandre, 2006), coliformes fecais e metais pesados, concentrados principalmente próximos a Joinville (Oliveira, 2006). Estes poluentes são espalhados para vários manguezais da $\mathrm{BB}$ devido ao efeito do fluxo das marés e velocidade e direção das correntes (Amorim et al., 2006).

Com o fechamento do Canal do Linguado (CL), houve alteração na salinidade nos dois lados do canal, sendo menor na porção norte e maior na porção sul. Também houve aumento do acúmulo de sedimentos nos mangues da porção norte, acúmulo de areia carreada pelas marés no interior do CL em Barra do Sul e o assoreamento da região do porto de São Francisco (IBAMA, 1998; Silva, 2011).

A remoção dos manguezais da BB ocorreu primeiramente devido à expansão urbana (ocupações irregulares) e industrial (portos). Souza (1991) comentou que a expansão da base econômico-industrial em Joinville na década de 1970 originou um grande fluxo migratório que, sem uma política habitacional, se refletiu na ocupação das áreas de manguezais. $\mathrm{O}$ autor também destacou os incentivos financeiros para urbanizar as áreas de manguezais invadidas e a especulação imobiliária. Girelli (2016) igualmente reconheceu as ocupações irregula- res e ainda identificou a extração de folhas de espécies arbóreas para obtenção de taninos em manguezais de Joinville. Além destes, Silva (1995) destaca outros tipos de impacto em manguezais, como o uso da madeira das árvores para a carvoaria e para a construção de cercas (moirões), o surto de lepidópteros desfolhadores (que atingiu 70\% da área total de manguezais com o desfolhamento de A. schaueriana) e a remoção dos mangues para construção de lagoas para criação de camarão e usos agropecuários.

A Baía Babitonga abriga dois portos, o de São Francisco do Sul (1955) e o de Itapoá (2011). Atualmente existem alguns projetos de ampliação da capacidade portuária em São Francisco do Sul. As supressões em manguezais são previstas para as obras do Terminal Marítimo Mar Azul (3,46 ha, Cabral, 2011), do estaleiro da CMO (5,93 ha, CMO, 2014) e do Terminal Graneleiro da Babitonga (13 a 36 ha em áreas de APP, TGB, 2014). Além destes, são citados projetos de ampliação do Terminal de Granéis de Santa Catarina e da ampliação do porto de São Francisco do Sul, um berço para navios de passageiros e do Terminal da Empresa Sadia (Cabral, 2011). Ainda a Worldport possui um projeto que prevê a construção de sete terminais e oito berços de atracação na orla da praia do Sumidouro, com provável impacto em manguezais e/ou marismas. Além da remoção da vegetação de manguezal, a construção de portos pode gerar efeitos secundários devido às alterações no padrão hidrológico e da dinâmica sedimentar, modificação no regime e alteração no fundo dos corpos d'água e poluição da água e do solo (Rosa et al., 2013; Hoffman, 2015).

No pontal do Capri, em São Francisco do Sul, Santos \& Horn-Filho (2006) identificaram como os principais tipos de impacto nas marismas e manguezais: a ocupação de áreas de preservação permanente de terras da marinha e de uso comum e a realização de dragagem na laguna de Capri. Essas atividades removeram parte da vegetação existente e causaram o soterramento da vegetação. Neste mesmo município, no Bairro Iperoba, Kilca et al. (2011) relataram que existe uma grande área 
contínua de manguezais e que em quase toda a sua extensão haviam inúmeros acessos feitos pelos moradores do bairro para chegar na BB. A construção destes acessos removeu parte da vegetação de mangues e marismas e alterou a hidrologia local pelo aterramento dos acessos com rejeitos de construção civil.

Outro fator recente que vem causando mortalidade em uma grande área (837 ha) de bosques homogêneos com $A$. schaueriana próxima de Joinville foi a ocorrência conjunta de dois fatores: a invasão da lagarta da teca (lepidóptero - Hyblaea puera) em janeiro de 2016 e a poluição química dos sedimentos por agentes ainda não detectáveis (Kilca, 2017). Todas estas ameaças passadas, recentes e futuras colocam em cheque todos os inúmeros serviços ambientais atribuídos aos manguezais, visto que não há uma política eficiente para a proteção destes ecossistemas na Baía Babitonga. Outras considerações sobre impacto e gerenciamento costeiro foram abordados em artigos do Especial Babitonga.

\section{Projetos e iniciativas realizadas e em andamento com relação aos man- guezais}

Alguns projetos e iniciativas já foram citados no item "Florística e estrutura dos manguezais". No entanto, são reconhecidos projetos desenvolvidos na área de educação ambiental e outros projetos estão em desenvolvimento sobre manguezais na $\mathrm{BB}$.

O projeto "Na Enchente da Maré: Uma Aventura no Berçário do Mar", premiado na $21^{\text {a }}$ Edição do Prêmio Embraco de Ecologia, em 2013, foi desenvolvido com crianças do Centro de Educação Infantil (CEI) Espinheiros e teve como objetivo coordenar uma visita guiada com professores, alunos e pais para observar e coletar o lixo dentro dos manguezais. Além disso, palestras sobre destinação final dos resíduos foram ministradas (Martin, 2014). Outro premiado projeto foi "Projeto Mangue: um Espaço de Vida, Encanto e Beleza", desenvolvido no Centro de Educação Infantil Ponte Serrada, no município de Joinville. O projeto envolvia crianças de 5 e 6 anos em um passeio de escuna para observar os impac- tos e entender a importância da preservação da água, vegetação e animais dos manguezais. Além das crianças e suas famílias, a comunidade em geral foi integrada ao projeto com palestras, exposições de fotos e com plantio de mudas de espécies frutíferas (Portal Brasil, 2014).

O Instituto Vidamar iniciou em 2016 dois projetos de inventários sobre os manguezais da Baía Babitonga: o primeiro projeto tem como objetivo descrever as mudanças na composição e estrutura dos manguezais em toda a baía em relação aos processos de sucessão secundária e zonação (salinidade e alagamento). Este estudo tem como objetivo abranger uma amostragem de 5 ha de manguezais (Kilca, 2017). O segundo projeto monitora trechos de manguezais com diferentes níveis de desfolhamento, mortalidade e estrutura em manguezais seriamente impactados pela predação pela lagarta-da-teca (Hyblaea puera (Cramer, 1777) e pela poluição aquática. Estes dois estudos irão revelar padrões de mudança na vegetação devidos às mudanças ambientais naturais e antrópicas, proporcionando um melhor entendimento para propor estratégias de conservação e recuperação dos manguezais na região.

Infelizmente não conhecemos nenhuma iniciativa para estudos no ecossistema de marismas na BB. Essa falta de estudos parece refletir a pouca representatividade em área ocupada pelas marismas na zona entremarés em relação aos manguezais. No entanto, existem áreas significativas de marismas para serem investigadas no corpo principal da BB ( $p$. ex.: bairro Iperoba, rio Morretes), no Canal do Linguado (talvez as maiores áreas de marismas) e Rio Palmital (zonas de transição entre o manguezal e as florestas de terra firme) (Kilca com. pess.). Devido aos diversos serviços ambientais reconhecidos pelas marismas, destacamos aqui a grande carência de estudos que busquem caracterizar, mapear e medir a cobertura das marismas, que são quase desconhecidas cientificamente na Baía Babitonga.

Por outro lado, as florestas de mangues apresentaram um maior número de estudos em diferentes regiões da BB que puderam esclarecer aspectos básicos de sua abrangência, cobertura, diversidade, ecologia e os principais 
impactos. Esta revisão buscou caracterizar os ecossistemas e identificar novas demandas para pesquisas que busquem a elaboração de políticas eficientes que conciliem o desenvolvimento econômico com a preservação e uso sustentável dos recursos naturais na Baía Babitonga.

\section{Agradecimentos}

Ao Grupo Pró-Babitonga e aos dois revisores deste artigo.

\section{Referências Bibliográficas}

AGNOLON, R. B. 2008. Comparação da produção da serapilheira nos manguezais ao norte e ao sul do Canal do Linguado, São Francisco do Sul/SC. Joinville. 19 p. (Monografia de Graduação. Curso de Biologia Marinha, Univille).

ALEXANDRE, M. R. 2006. Caracterização química do extrato orgânico dos sedimentos recentes da Baía da Babitonga - SC. Florianópolis. 118 p. (Tese de Doutorado. Centro de Ciências Físicas e Matemáticas, UFSC).

AMORIM, J. C. C., ELFRINK, B., CARVALHO, J. L.B. \& CASAROLI, L. F. R. 2006. Diagnóstico dos estudos de circulação de água no canal do Linguado e Baía da Babitonga. In CREMER, M. J.; MORALES, P. R. D. \& OLIVEIRA, T. M. M. (Orgs). Diagnóstico ambiental da Baía da Babitonga. Ed. Univille, Joinville, cap. 3: 81-111.

BARTZ, M. C., MELO-JÚNIOR, J. C. F. \& LARCHER, L. 2015. Variação morfológica de $L a-$ guncularia racemosa (L.) C.F. Gaertn. (Combretaceae) em áreas de manguezal e de transição entre manguezal e floresta de restinga. Biotemas, 28(1): 21-29.

BERGER, J. Z. 2008. Vascular flora of the Babitonga Bay region (Santa Catarina, Brazil): diversity and origins. ErlangenNürnberg, Deutschland. 215 p. (Doktorgrades, Der Naturwissenschaftlichen Fakultät, FAU).

BERTOLLI, G. B. \& ZANOTELLI, C. T. 2009. Caracterização da ocupação do ecossistema de manguezal e aspectos de saúde da população do bairro vila Cubatão, Joinville - SC. Holos Env., 9(2): 236-256.

CABRAL, E. B. 2011. Estudo geográfico do porto de São Francisco do Sul e do terminal de Itapoá-SC. Florianópolis. 288p. (Dissertação de Mestrado. Instituto de Geociências, UFSC).

CEPSUL. Centro de Pesquisa e Gestão de Recursos Pesqueiros do Litoral Sudeste e Sul. 2005. Reserva da Babitonga. Itajaí, CEPSUL/ IBAMA. 27p. Disponível em: http:// solamac.org/babitonga/

babitonga prop final.pdf. Acesso em: 20 dez. 2016.

CMO. Construção e Montagem Offshore S.A.. 2014. RIMA: Implantação do Estaleiro CMO em São Francisco do Sul, Santa Catarina. Disponível em: http://www.fatma.sc.gov.br/ upload/rima/RIMA-Estaleiro\%20CMO-print -web.pdf. Acesso: 20 fev. 2017.

CONSEMA. 2014. Resolução CONSEMA no 51. Reconhece a Lista Oficial das Espécies da Flora Ameaçada de Extinção no Estado de Santa Catarina e dá outras providências. Disponível em: http://www.sds.sc.gov.br/ index.php/biblioteca/consema/ legislacao/ resolucoes/325-resolucao-consema-no512014-1/file. Acesso em: 20 mar.2017.

COSTA, C. S. B. \& DAVY, A.J. 1992. Coastal saltmarsh communities of Latin America. In SEELIGER,U. (ed.). Coastal Plant Communities of Latin America. San Diego, Academic Press. Inc., chap. 12: 179-199.

CUNHA, S. R.; TOGNELLA-DE-ROSA, M. M. P. \& COSTA, C. S. B. 2006. Salinity and flooding frequency as determinant of mangrove forest structure in Babitonga Bay, Santa Catarina State, Southern Brazil. J. Coast. Res., Special Issue 39: 1175-1180.

DORNELLES, S. S., MOREIRA, G. M. \& FREITAS, L. M. 2006. Caracterização da estrutura vegetal dos manguezais do Canal do Linguado, Baía da Babitonga. In CREMER, M. J. (ed.). Diagnóstico ambiental da Baía da Babitonga. Univille, Joinville, cap. 7:187-199.

DUARTE, G.M. 1988. O futuro do litoral de Santa Catarina. Revista Geosul, 3(6): 39-52.

DUKE, N. C., MEYNECKE, J. O. DITTMANN, S., ELLISON, A., ANGER, K., BERGER, U., 
CANNICCI, S. DIELE, K., EWEL, K., FIELD, C., KOEDAM, N.M LEE, S., MARCHAND, C., NORDHAUS, I. \& DAHDOUH-GUEBAS, F. 2007. A world without mangroves? Science 17 (5834):41-42.

DUKE, N. C. 2011. Mangrove Islands. In HOPLEY, D. (Ed.). Encyclopedia of modern coral reefs. Structure, form and process. Dordrecht, Springer: 653-655.

FAVA, I. R. S. 2016. Caracterização e setorização das ilhas da Baía Babitonga, Santa Catarina. Joinville, 33 p. (Monografia de Graduação. Departamento de Ciências Biológicas, UNIVILLE).

FAO. Food and Agriculture of the United Nations. 2007. The world's mangroves 1980-2005. Rome, Fao Forestry Papers. 77p.

GIRELLI, F. 2016. Um olhar sobre o manguezal: as representações dos moradores do bairro Espinheiros numa perspectiva do patrimônio natural. Joinville. 111 p. (Dissertação de Mestrado. Patrimônio Cultural e Sociedade, Univille).

GIRI, C., OCHIENG, E., TIESZEN, L. L., ZHU, Z., SINGH, A., LOVELAND, T., MASEK, J. \& DUKE, N. 2011. Status and distribution of mangrove forests of the world using earth observation satellite data. Glob. Ecol. Biogeogr., 20: 154-159.

GRACE, V. B., MAS-PLAC, J., NOVAIS, T. M. O., SACCHI, E. \& ZUPPIA, G. M. 2008. Hydrological mixing and geochemical processes characterization in an estuarine/mangrove system using environmental tracers in Babitonga Bay (Santa Catarina, Brazil). Cont. Shelf Res., 28: 682-695.

HANSEL, F.A. 2000. Análise de biomarcadores lipídicos em sedimentos de manguezais. Florianópolis. 94 p. (Tese de Mestrado em Química. Departamento de Química, UFSC).

HOFFMAN, R.M. 2015. Impactos ambientais causados pelas obras de construção e ampliação de portos marítimos no Brasil com ênfase nas comunidades pesqueiras. Brasília, Câmara dos Deputados. 39p.

IBAMA. Instituto Brasileiro do Meio Ambiente e dos Recursos Naturais Renováveis. 1998. Proteção e controle de ecossistemas costeiros: manguezal da Baía de Babitonga. Brasília, IBAMA. 146p.

IBGE. Instituto Brasileiro de Geografia e Estatística. 2012. Manual Técnico da Vegetação Brasileira. 2. ed. Rio de Janeiro, IBGE. 270p.

IBGE. 2016. Estimativas da população residente para os municípios e para as unidades da federação. Disponível em: <https:// www.ibge.gov.br/estatisticas-novoportal/ sociais/populacao/9103-estimativas-depopulacao.html? edicao $=9112 \& \mathrm{t}=$ resultados $>$. Acesso em 10 jan 2017.

ICMBIO. 2015. Portaria ICMBio $\mathbf{n}^{\circ}$ 9. Aprova o Plano de Ação Nacional para a Conservação das Espécies Ameaçadas e de Importância Socioeconômica do Ecossistema Manguezal. Disponível em: <http://www.icmbio.gov.br/ portal/images/stories/documentos/

porta-

ria 09 de 29 de janeiro de 2015.pdf $>$.

Acesso em: 02 jan. 2017.

ICMBIO. Instituto Chico Mendes de Conservação da Biodiversidade. 2018. Atlas dos Manguezais do Brasil. Brasília: ICMBIO, 176p. Disponível em: http://www.icmbio.gov.br/ portal/images/stories/manguezais/ atlas dos manguezais do brasil.pdf. Acesso: 02 jan 2017.

KARGER, A.D. 1996. Análise físico-químico e bacteriológica da água intersticial do manguezal da ilha da Vaca, Baía da Babitonga, Joinville, SC. Joinville. 38 p. (Monografia de Graduação. Departamento de Ciências Biológicas, UNIVILLE).

KATHIRESAN, K. \& BINGHAM, B.L., 2001. Biology of mangroves and mangrove ecosystems. Adv. Mar. Biol. 40: 81-251.

KILCA, R. V., ALBERTI, L., SOUZA, A. \& WOLFF L. 2011. Estrutura de uma floresta de mangue na Baía da Babitonga, São Francisco do Sul, SC. CeN., 33, 57-72.

KILCA, R.V. 2017. Monitoramento do desfoliamento e da mortalidade de manguezais na Baía da Babitonga-SC. Relatório final enviado ao Ministério Público de Joinville. São Francisco do Sul, Instituto Vidamar. 7op.

KLEIN, R. M., SMITH, L. B. \& WASSHAUSEN, D. C. 1981. Flora Ilustrada Catarinense: I Par- 
te Gramíneas. Edição Herbário Barbosa Rodrigues, Itajaí. 436p.

LARCHER, L. 2016. Estrutura de manguezais sulbrasileiros e sua relação com o gradiente de planície de inundação. Curitiba. 130 p. (Tese de Doutorado. Programa de Pós-Graduação em Ecologia e Conservação, UFPR).

LUGO, A. E. \& SNEDAKER, S. C. 1974. The ecology of mangroves. Annu. Rev. Ecol. Evol. Syst., 5: 39-64.

LÜTTGE, U. 2008. Physiological ecology of tropical plants. 2.ed. Berlin, Springer. 457p.

MARTIN, L. 2014. Projeto com crianças de Joinville incentiva a preservação do mangue. Jornal de Santa Catarina. Disponível em: http:// doczz.com.br/doc/393002/projeto-comcrian\% $3 \%$ A7as-de-joinville-incentiva-apreserva\% $3 \% \mathrm{C}_{3} \% \mathrm{C}_{3} \% \mathrm{~A} 30$. Acesso em: 20 abr. 2017.

OLIVEIRA, F. A. 2006. Estudo do aporte sedimentar em suspensão na Baía da Babitonga sob a ótica de geomorfologia. São Paulo. 286 p. (Tese de Doutorado. Faculdade de Filosofia, Letras e Ciências Humanas, USP).

OLIVEIRA, F.A. \& TRETER, U. 2007. Diferenciação espacial de sedimentos na faixa de manguezal da Baía da Babitonga. Resumos. ABEQUA. Disponível em: http:// www.abequa.org.br/ trabalhos/2007 fabiano quatcost.pdf. Acesso em: 03 jan.2017.

PAN Manguezais. Plano de Ação Nacional de Conservação dos Manguezais. 2015. Disponível em: https://uc.socioambiental.org/ destaque/plano-de-a\% $3 \% \mathrm{C}_{3} \% \mathrm{~A}_{3} \mathrm{C}_{3} \% \mathrm{~A} 30-$ nacional-de-conserva\% $\mathrm{C}_{3} \% \mathrm{~A} 7 \% \mathrm{C}_{3} \% \mathrm{~A} 30$-dos -manguezais. Acesso: 14 fev. 2017.

PANITZ, C. M. N. 1987. Perfil funcional da gramínea Spartina alterniflora no mangue do rio Itacorubi, Ilha de Santa Catarina, Florianópolis, Brasil $\left(27^{\circ} 35^{\prime} \mathrm{S}-48^{\circ} 31^{\prime} \mathrm{W}\right)$. Publicações Academia Ciências, 54(1): 100-116.

PANITZ, C. M. N. 1992. Ecological aspects of a saltmarsh ecosystem in Santa Catarina Island, Brazil. In SEELIGER, U. (ed.). Coastal plant communities of Latin America. San Diego, Academic Press. Inc, Cap. 14: 213-230.

PORTAL BRASIL.2014. Projeto escolar sobre pre- servação de mangue é desenvolvido em Joinville (SC). Disponível em: http:// www.brasil.gov.br/educacao/2014/07/ projeto-escolar-sobre-preservacao-demangue-e-desenvolvido-em-joinville-sc. Acesso em: 12 abr.2017.

PARIDA, A. K. \& JHA, B. 2010. Salt tolerance mechanisms in mangroves: a review. Trees, 24(2):199-217.

ROBERTSON, A. \& DUKE, N. C. 1990. Recruitment, growth and residence time of fishes in a tropical Australian mangrove system. Estuar. Coast. Shelf Sci., 31: 723-743.

ROSA, R. A., SEVEGNANI, L. \& SCHROEDER, E. 2013. Formação Pioneira com Influência Fluvio-Marinha - Manguezal. In SEVEGNANI, L. \& SCHROEDER, E. (orgs). Biodiversidade Catarinense: Caracterização, potencialidades e ameaça. Blumenau, Edifurb. Cap. 2: 128133.

SANDILYAN, S. \& KATHIRESAN, K. 2012. Mangrove conservation: a global perspective. Biodivers. Conserv., 21:3523-3542.

SANTOS, C. R. \& HORN-FILHO, N.O. 2006. Impactos ambientais decorrentes da ocupação antrópica no pontal do Capri, ilha de São Francisco do Sul, SC, Brasil. Geografias, 2 (1):34-46.

SCHAEFFER-NOVELLI, Y., CINTRON-MOLERO G., ADAIME R. R. \& CAMARGO T. M. 1990. Variability of mangrove ecosystems along the Brazilian coast. Estuaries, 13 ( 2 ): 204-218.

SCHAEFFER-NOVELLI, Y., SORIANO-SIERRA, E.J., VALE, C. C., BERNINI, E., ROVAI, A. S., PINHEIRO, M. A. A., SCHMIDT, A. J., ALMEIDA, R., COELHO JÚNIOR, C., MENGHINI, R. P., MARTINEZ, D. I., ABUCHAHLA, G. M. O., CUNHA-LIGNON, M., CHARLIER-SARUBO, S., SHIRAZAWAFREITAS, J. \& CINTRÓN-MOLERO, G. 2016. Climate changes in mangrove forests and salt marshes. Braz. J. Oceanogr., 64(2):37-52.

SILVA, F. J. B. 1995. Unidades de Conservação e desenvolvimento regional: um estudo sobre a região da Baía da Babitonga-SC. Florianópolis. 146 P. (Dissertação de Mestrado. Departamento de Geociências, UFSC).

SILVA, M. C. M. 2001. Diagnóstico ambiental do 
manguezal da baía da Babitonga, Santa Catarina, através do uso de indicadores ecológicos, parâmetros foliares e produtividade de serapilheira. Florianópolis. 112p. (Dissertação de Mestrado. Departamento de Engenharia Sanitária e Ambiental, UFSC).

SILVA, L. S. 2011. Alterações morfodinâmicas no Canal do Linguado pela remoção do dique que o separa da Baía da Babitonga (SC). Porto Alegre. 198 p. (Tese de Doutorado. Instituto de Geociências, UFRGS).

SOARES, M. L., ESTRADA, G. C. D., FERNANDEZ, V. \& TOGNELLA, M. M. P.2012. Southern limit of the Western South Atlantic mangroves: assessment of the potential effects of global warming from a biogeographical perspective. Estuar. Coast. Shelf Sci.,101: 44-53.

SOBRINHO, R. J. S., BRESOLIM, A. \& KLEIN, R.M. 1969. Os manguezais na Ilha de Santa Catarina. Insula, 2: 1-21.

SORIANO-SIERRA, E. J. 1990. Ecossistemas de marismas, II - a produção primária. In Simpósio de Ecossistemas da Costa Sul e Sudeste Brasileira, 2. 1990, Águas de Lindóia. Anais ... Águas de Lindóia, 1990. v. 2, p. 150-157.

SORIANO-SIERRA, E. J. 1999. Ecossistemas de marismas da Lagoa da Conceiçao. II. Fitocenosis. O ecossistema da Lagoa da Conceição. Série Fepema, 4:171-184.

SORIANO-SIERRA, E. J., SCHAEFFERNOVELLI, Y., ROVAI, A. S., BERNINI, E. \& ABUCHAHLA, G. M. O. 2015. Monitoramento da estrutura de pradarias de marismas. In TURRA, A. \& DENADAI, M. R. (orgs). Protocolos para o monitoramento de habitats bentônicos costeiros - rede de monitoramento de habitats bentônicos costeiros - ReBentos. São Paulo, Instituto Oceanográfico da Universidade de São Paulo. p. 116-121.

SOUZA, L. A. de. 1991. O processo de ocupação das áreas de mangues em Joinville: agentes, estratégias e conflitos. 127 P. (Dissertação de Mestrado em Geografia, Departamento de Geociências, UNIVILLE)

SOUZA, M. L. E. R., FALKENBERG, D.B., AMARAL, L. G., FRONZA, M., ARAUJO, A. C. \& SÃ M. R. 1992. Vegetação do Pontal de Daniela, Florianópolis, SC, Brasil. I. Levantamento florístico e mapa fitogeográfico. Insula, 21: 87 $-117$.

SOUSA, M. S., IENSEN, I. R. R., LIMA, N. R., BRANDT, I. L. S. \& OLIVEIRA, F.A. 2016. Caracterização fitossociológica e sedimentar de manguezais: estudo de caso na baía da Babitonga (São Francisco do Sul/SC). Anais. XI SINAGEO, Maringá, 2016. Disponível em: http://www.sinageo.org.br/2016/ trabalhos/7/7-444-1224.html. Acesso em: 10 mar.2017.

TGB. Terminal Graneleiro da Babitonga. 2014. RIMA: implantação do Terminal Graneleiro da Babitonga - TGB em São Francisco do Sul, Santa Catarina. Disponível em: http:// www.fatma.sc.gov.br/ckfinder/userfiles/ arquivos/Rimas/RIMA TGB 2014-12-15-1IMA TGB rev16 web RED.pdf. Acesso: 20 jan. 2017.

TOGNELLA, M. M. P. 1998. Estrutura dos bosques. In: IBAMA. Proteção e controle de ecossistemas costeiros: manguezal da Baía da Babitonga. Série Estudos de Pesca, n. 25. Brasília, IBAMA, p. 38-48.

UICN. The International Union for Conservation of Nature. 2017. The IUCN Red List of Threatened Species. Disponível em: http:// www.iucnredlist.org/. Acesso em: 10 fev. 2017.

UN (United Nations). 2016a. Mangroves. In: United Nations. First global integrated marine assessment. World ocean assessment I. Chap. 48. 18p. Disponível em: http:// www.un.org/depts/los/global reporting/ WOA RPROC /Chapter 48.pdf. Acesso em: 10 mar. 2017.

UN (United Nations). 2016b. Salt marshes. In: United Nations. First global integrated marine assessment. World ocean assessment I. Chap. 49. 9p. Disponível em: http:// www.un.org/depts/los/global reporting/ WOA RPROC/ Chapter 49.pdf. Acesso em: 10 mar.2017.

UNEP. United Nations Environment Programme. 2014. The importance of mangroves to people: a call to action. van BOCHOVE, J., SULLIVAN, E. \& NAKAMURA, T. (eds). Cambridge, UNEP-WCMC. 128 pp. 
VALGAS, I.S. 2009. As marismas de Spartina alterniflora e os taboais de Typha domingensis do sistema estuarino de Laguna (Santa Catarina, Brasil): distribuição espacial, estrutura e macrofauna associada. Curitiba. $62 \mathrm{p}$. (Dissertação de Mestrado. Pós-Graduação em Ecossistemas Costeiros e Oceânicos, UFPR). 